\title{
The role of the user experience on sustainable aspects of Product Design
}

\author{
Davi Neiva Alves ${ }^{1}$ Matheus Tymburibá Elian² Eduardo Romeiro Filho ${ }^{3}$ \\ ${ }^{1}$ Universidade do Estado de Minas Gerais, Escola de Design, Av. Antônio Carlos, 7545 - São Luiz - Belo Horizonte, Minas Gerais, \\ Brazil \\ ${ }^{2}$ Universidade do Estado de Minas Gerais, Escola de Design, Av. Antônio Carlos, 7545 - São Luiz - Belo Horizonte, Minas Gerais, \\ Brazil \\ ${ }^{3}$ Universidade do Estado de Minas Gerais, Escola de Design, Av. Antônio Carlos, 7545 - São Luiz - Belo Horizonte, Minas Gerais, \\ Brazil
}

\begin{abstract}
The concern about sustainability in design is increasingly inherent to projects in society today, where the harms of projects that did not have the necessary concern about sustainability already show bad environmental results. However, even though a project can be considered sustainable, it only becomes economically viable for companies, if it is accepted by users. To achieve this goal, constant comprehension and monitoring of the user's perception and experience of sustainable adjectival products becomes essential. Despite the already mentioned importance of this comprehension, the literature that studies in parallel, user experience and sustainability in design, is still limited. Aiming to contribute to a better understanding of the theme, the article demonstrates examples where there is a search for the perception of user experience related to sustainable products and concludes suggesting a future perspective for the theme.
\end{abstract}

Keywords. User experience, sustainability, sustainable aspects, product design.

\section{Introduction}

For a better comprehension of the whole, an approach for sustainability and user experience will be made in the introduction. According to Sacha Kagan (2008), sustainability is defined as a set of activities that are divided into three strands: social justice, ecological integrity and economic well-being. Sacha finalizes his definition in the following terms:

"One of the innovative features of the concept of sustainability is that it draws a whole range of seemingly paradoxical conciliations: the reconciliation of normative and hitherto supposedly "positive" science, the reconciliation of economics with ecology, reconciliation of matter and culture Society, technology and the environment) and the reconciliation of intra-generational and intergenerational justice (i.e. the needs of the generations present across the globe and the needs of future generations). Sustainability is a new concept for an era of hypercomplexity, where the challenges of increasingly globalized economic exchanges as well as cultural exchanges are combining with the challenge of global and local interconnected ecological and social crises."
The concern about design for sustainability, according to Bitencourt (2001), has been growing in several countries due to increasingly demanding legislation to the possible harmful effects that the misuse of materials can cause to the environment, the use of the same in methods and the understanding of user perception as product sustainability increasingly crucial factors.

The user experience, according to ISO 9241-210: 2010 , is a set of perceptions and reactions of a person that result from the intended use or use of a product, system or service is defined. When applied to design, the user experience is based on the satisfaction and pleasure obtained through the use of the object in the case of physical products. A pleasant experience can be the result of challenges, small rewards, and fun obtained in this interaction with the product. According to Carroll (2004):

"Things are fun when they attract, capture and hold our attention to the provocation of new or unusual perceptions, awakening emotions in contexts that typically do not awake any, or not arousing any emotion in contexts that should awaken them. Things are fun when they have challenges or puzzles to us as we try to create meanings and construct interpretations."

\footnotetext{
${ }_{\text {dneivaalves@gmail.com }}^{2}$
} 
Brandtzæg et al. (2003) present three guidelines for the design of pleasant technologies, and they are: the control and participation by the users, with appropriate challenge; variation and multiple opportunities; and social opportunities in terms of co-activity and social cohesion.

These observed aspects are essential for the design of new products to create a more lasting relationship with the user, influencing even in the period of obsolescence. The interaction with the product that generates the experience has to be simple, yet challenging and pleasurable, and still stimulate intangible product values, such as the value of esteem, which is one of the differential aspects for the user's choice.

While designing, and designing new products, thinking about sustainable aspects is an essential prerequisite. The lifestyle of a large part of the world's population is characterized by high levels of consumption, and this is responsible for a huge increase in the extraction of resources and environmental problems. In industrialized countries, housing, mobility, food and electricity use account for more than $70 \%$ of the impact of domestic consumption (LIEDTKE et al. 2012; ETC/SCP 2009).

So we can see that design focused on the user experience can be used as a tool to expand sustainable aspects, directly influencing the level of individual consumption, since it is possible to design opportunities to extend the useful life of products through reuse, sharing, among other ways.

\section{Analysis and Discussion}

The user experience regarding the perception of sustainable products is still largely (mainly lay in the subject) related to products that are not efficient or have a reuse aspect in materials.

In his dissertation, Santos (2012), observing the growing number of design projects and academic studies about sustainability, interviews a focus group with the purpose of understanding the user's perception about sustainable products. The products most cited by the 30 interviewees, in the majority, (18 of them) lay people in relation to design and sustainability issues when questioned about products that refer to the term sustainability, the answers were, recycled paper, Gook sandals and "ecological" bags (Figure 1), products, which have a sustainable character as a perceivable factor in their respective appearances, whether by colours, materials or even the messages that they stamp or the impression that companies which produce them want to show to their clients. But it is also important to highlight that other elements are necessary to the support the relationship between customers and companies, such as websites, applications and shops.
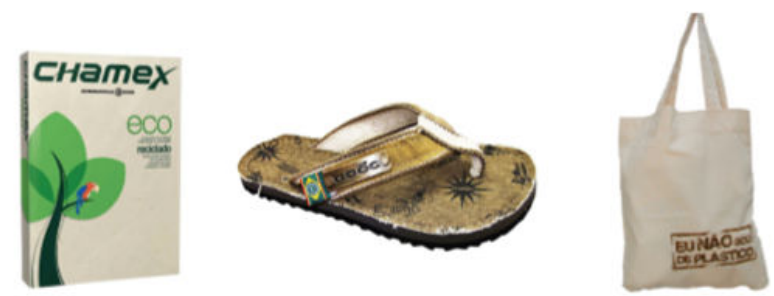

Figure 1. Recycled paper, Gook sandals and "ecological" bag.

Source. Santos (2012).

It is also observed in the Santos experiment (2012) that the lack of information about the subsequent processes in the life cycle of products was a reason for the users to form their opinion in a neutral or negative way about the products studied, confirming that access to information makes users decide more convincingly and have more active posture in improving the products they consume.

However, in the 21 st century this perception tends to change, with technological growth being a catalyst in this process, together with a greater awareness of the social and economic damages of non-ecological production decisions, and the intelligent design of products that present sustainable characteristics not necessarily linked to the material used in its manufacture. Since, according to Kagan (2008), the cultural basis for sustainability has been neglected for years, the author makes this following terms:

"Either through ignorance on the part of political, economic, and scientific elites, or perhaps because they realize the radical implications that a cultural strategy for sustainability would have. But a growing number of cultural actors have denounced this situation in recent years and began to promote cultural strategies for sustainability and advocating recognition of culture as the central dimension to the process of pursuing sustainability."

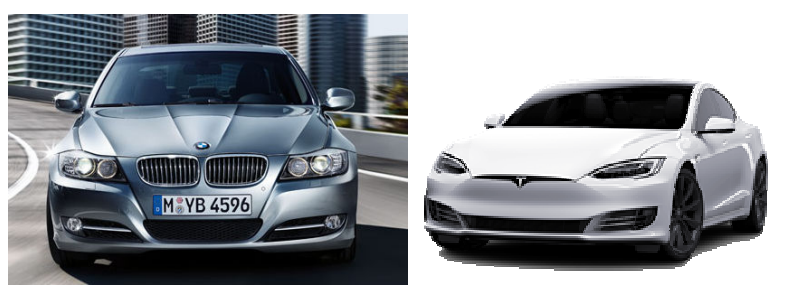

Figure 2. BMW 320d and Tesla Model S, cars fuelled by fossil combustible and electric power, products with different perception of sustainability on its aspects.

Source. BMW and Tesla websites (2016).

The figure 2 shows two cars, one of them fuelled by fossil combustible (BMW 320d), and the other one by electric power (Tesla Model S). At first sight, when analyzing the energetic matrix of both cars, is possible to figure that the electric vehicle could impact less on the 
emission of $\mathrm{CO} 2$, however the production of its energetic matrix generate a larger amount of emissions than the burn of fossil fuel used by the combustion powered model (BMW 2016). Some countries, like Singapore, have a concerning about these products due its environmental impacts, one of the ways found to discourage the large consumption of these products was creating a new tax. A superficial analysis of the sustainable aspects made a citizen from Singapore to be taxed on over 15 thousand dollars due the ecological footprint of the Tesla Model $\mathrm{S}$ that he had imported. (SINGAPORE GOVERNMENT 2016; TAN 2016).

In many situations, when the consumer is purchasing a product, or contracting a service that have allegedly eco-friendly specs, he doesn't have real knowledge about the life cycle, and how that product really acts on the environmental issues. In the majority of the scenarios, the decision of purchase a product is related to a first glance analysis of the cost-benefit relation, not to a superior environmental performance.

The experience resulting from interaction with a given product causes the user to express their judgments about it. The hierarchy of needs allows us to categorize a user's judgments into different levels. Green and Jordan (2002) propose the following hierarchy of these needs at four different levels: Level 1, regarding the safety and well-being; Level 2, regarding the functionality; Level 3, regarding usability; and Level 4 , regarding the pleasure.

The current context of the market makes design to become more and more related to the relationship between the human being and the surrounding environment. The constant advancement of technology has enabled the equalization of most of the needs of the hierarchy proposed by Green and Jordan (2002), except when it comes to pleasure, which can also mean the satisfaction of expectation. This satisfaction can only be reached if the needs, desires and expectations about a given product are matched while experiencing that same product.

Experience design, besides being a crucial factor for the highlight of products in the current market, allows that the design of new products can go beyond the objective solutions of the problems of the users, finding also solutions that can strengthen the sustainable aspects, and its perception, in a product or service.

\section{Conclusion}

The consciousness of consumption is necessary to make the concerns about the sustainable aspects relevant, and drive the consumer, in its consumption philosophy, to care about this aspect on a product. The sustainability culture allows that the conception of new projects influences on the creation of new social and consumption paradigms. These cultures of sustainability need to be in a continuous re-actualization and selfcritical exploration, otherwise they will lose their capacity of renewal the society paradigms due stagnations of consumption profiles (KAGAN, 2008).
"Cultures of sustainability may inspire hope, but their strength is also their vulnerability. As soon as they crystallize into fixed states, closing their boundaries and fixing their borders, they risk losing their elasticity and porosity, down the path of autopoiesis. Cultures of sustainability are a matter of constant self-critical exploration. They require a continuous re-actualization of reflexive competences. For this reason, they demand an artful practice of life."

Consumption is intrinsically linked to sustainability, but it's valid to notice that it's not just to survive, not even to get warm and protect us from the rain. We eat to socialize, and dress to express our identity, feeling good with ourselves. Consumption is a process, and as such, forms itself in an identity and lifestyle-building project, as Dobers (2005) mentions:

"Although ranging widely in levels of wealth, the consumer class people are archetypal users of television, telecommunication and the Internet, along with contemporary media culture and commercial ideologies that these widely distributed products transmit. (...) One would assume that most of the members of the consumer class are found in Western industrialized nations. Interestingly enough, almost half of them come from the 'developing' world. Although there is clearly an increasing gap between the few very rich and the many very poor, it suffices here to say that a material lifestyle and consumer culture has become widely accessible to an increasingly growing middle class throughout the world. Obviously, an increased (over)consumption has become a problem in both developed economies such as Europe and the Northern Americas, and the economically growing, but in many ways still developing, economies in Asia and Africa. (...) On a general level of human cognition, consumption is thereby seen as an attempt to escape the boredom of everyday life (...)."

A continuous analysis of design concepts, and concepts with these characteristics, especially in a consumer society, as the current one, intensifies the concern about the ecological footprint of products, and how it tends to grow, as described by Ashby and Johnson (2002):

“(...) design is not a meaningless exercise in styling and it is not an isolated exploration of technology. What matters is the process of finding solutions that are meaningful to people, that enable new experiences and inspire and create positive impacts in society and in our own daily lives. Today, people are 
looking for products that are sustainable and lovable, and it is the job of a designer to create those products. We need to evolve from an industrial society that is driven by consumerism to one that respects and admires materiality and efficiency."

It is noticed, then, that the user experience when applied in new product designs, must also reflect the sustainable aspects inherent to the own consumption. The role of the designer, in this design conception of the tangible and intangible aspects, is to intervene so that the user's consumption intention and his interaction with the object produce the minimum ecological impact without decreasing the value of esteem, and consumption desire, of the object.

It is concluded that the user experience, projected and applied to new products, when contextualized by the economic, cultural and social respective scenarios, can maximize the sustainable aspects, and its perception by the users.

The sustainability applied to the design of new projects, tends to be only effective when it meets the requirements obtained in the relation of the user with consumption, and its experience with other products. The user experience will act as a maximizing agent of tangible and intangible values of the products or services, while minimizing the damages of the ecological footprint, because it allows the interaction between human-product to be enriched and more durable through the perception and understanding of values related to the project.

\section{References}

ASHBY, M. F.; JOHNSON, K. Materials and Design The art and science of materials selection in Product Design. Butterworth Heineman, Oxford. 2002, p. 4.

BMW. Best in class: 24 models with no more than $140 \mathrm{~g} / \mathrm{km}$ CO2 - BMW 320d Sedan. 2016. Retrieved from:

$<$ http://www.bmw.com/com/en/insights/technology/effi cient dynamics/phase $2 / \mathrm{co} 2$ modelfinder/3er sedan 32 0d.html>. Last access: December $8^{\text {th }}, 2016$

BRANDTZÆG, P. B.; ASBJØRN, F.; HEIM, J. Enjoyment: lessons from Karasek - Introduction to Funology, Springer Netherlands, 2005, p. 55-65.

CARROLL, J. M. Beyond Fun. Interactions, 2004, p. 3840.

DOBERS, P.; STRANNEGARD, L. Design, Lifestyles and Sustainability. Aesthetic Consumption in a World of Abundance. Mälardalen University, Västerås, 2005.

ETC/SCP (2009). Environmental pressures from European consumption and production. ETC/SCP Working Paper 1/2009, European Topic Centre on
Sustainable Consumption and Production, Copenhague, 2009 .

GREEN, W. S.; JORDAN, P. W. Pleasure with products: Beyond usability. London: Taylor \& Francis, 2002.

ISO. ISO: 9241-210:2010 - Ergonomia da interação sistema humano, International Organization for Standardization, part 210, 2010

KAGAN, S. Cultures of sustainability and the aesthetics of the pattern that connects. Leuphana Universität Lüneburg, Lüneburg, 2008.

LIEDTKE, C.; WELFENS, M. J.; ROHN, H.; NORDMANN, J. LIVING LAB: user-driven innovation for sustainability. International Journal of Sustainability in Higher Education, Vol. 13, Issue 2, 2012, p. 106-118.

SANTOS, I. M. AVALIAÇÃO DA PERCEPÇÃO DOS USUÁRIOS SOBRE A COMUNICAÇÃO DA SUSTENTABILIDADE EM PRODUTOS: O MODELO PERSUS. Dissertação (mestrado) - Universidade do Estado de Minas Gerais, Pós graduação Stricto Senso em Design, Inovação e Sustentabilidade, 2012.

SINGAPORE GOVERNMENT. Land Transport Authority - Tax structure for cars. 2016. Retrieved from: $<$ https://www.lta.gov.sg/content/ltaweb/en/roads-andmotoring/owning-a-vehicle/costs-of-owning-avehicle/tax-structure-for-cars.html>. Last access: December $8^{\text {th }}, 2016$.

TAN, C. Electric car Tesla slapped with \$15,000 tax surcharge. The Straits Times. 2016. Retrieved from : $<$ http://www.straitstimes.com/singapore/transport/electri c-car-tesla-slapped-with-15000-tax-surcharge $>$. Last access: December $8^{\text {th }}, 2016$.

TESLA. Model S. 2016. Retrieved from: $<$ https://www.tesla.com/models $>$. Last access: December 8th, 2016. 